\title{
Radiation-induced brain injury: low-hanging fruit for neuroregeneration
}

\author{
Terry C. Burns, MD, PhD, ${ }^{1}$ Ahmed J. Awad, MD, ${ }^{2,3}$ Matthew D. Li, BS, ${ }^{4}$ and Gerald A. Grant, MD ${ }^{1}$ \\ 'Department of Neurosurgery and Institute for Stem Cell Biology and Regenerative Medicine, Stanford University, Stanford, \\ California; ${ }^{2}$ Department of Neurosurgery, Icahn School of Medicine at Mount Sinai, New York, New York; ${ }^{3}$ Faculty of Medicine \\ and Health Sciences, An-Najah National University, Nablus, Palestine; and ${ }^{4}$ Stanford University School of Medicine, Stanford, \\ California
}

Brain radiation is a fundamental tool in neurooncology to improve local tumor control, but it leads to profound and progressive impairments in cognitive function. Increased attention to quality of life in neurooncology has accelerated efforts to understand and ameliorate radiation-induced cognitive sequelae. Such progress has coincided with a new understanding of the role of CNS progenitor cell populations in normal cognition and in their potential utility for the treatment of neurological diseases. The irradiated brain exhibits a host of biochemical and cellular derangements, including loss of endogenous neurogenesis, demyelination, and ablation of endogenous oligodendrocyte progenitor cells. These changes, in combination with a state of chronic neuroinflammation, underlie impairments in memory, attention, executive function, and acquisition of motor and language skills. Animal models of radiation-induced brain injury have demonstrated a robust capacity of both neural stem cells and oligodendrocyte progenitor cells to restore cognitive function after brain irradiation, likely through a combination of cell replacement and trophic effects. Oligodendrocyte progenitor cells exhibit a remarkable capacity to migrate, integrate, and functionally remyelinate damaged white matter tracts in a variety of preclinical models. The authors here critically address the opportunities and challenges in translating regenerative cell therapies from rodents to humans. Although valiant attempts to translate neuroprotective therapies in recent decades have almost uniformly failed, the authors make the case that harnessing human radiation-induced brain injury as a scientific tool represents a unique opportunity to both successfully translate a neuroregenerative therapy and to acquire tools to facilitate future restorative therapies for human traumatic and degenerative diseases of the central nervous system. http://thejns.org/doi/abs/10.3171/2016.2.FOCUS161

KEY WORDS radiation; brain injury; neuroregeneration; oligodendrocyte progenitor cell; transplantation; myelination; neurogenesis

$\Delta$ LTHOUGH brain radiation therapy is critical to the management of primary and metastatic brain tumors, cognitive impairments caused by chemotherapy and radiation are increasingly recognized. In adults, impairments occur in up to $50 \%-90 \%$ of patients within 3-6 months after fractionated whole-brain radiation therapy (WBRT) ${ }^{8,24}$ Long-term survivors of childhood brain radiotherapy are most severely affected, experiencing double-digit declines in IQ, vocational restriction, and an elevated incidence of psychiatric impair- ments. ${ }^{45,52,53}$ Neurooncology outcomes have historically focused on survival. However, as outcomes have progressively improved for several malignancies, there has been an increasing need to preserve and improve the quality of life, not just overall survival. As perhaps the most severe and widespread form of iatrogenic brain injury, much remains to be learned about radiation-induced brain injury - the cognitive price of prolonged survival. Excitingly, compelling prospects exist to not only better understand human CNS pathophysiology through this condition, but

ABBREVIATIONS BrdU = bromodeoxyuridine; ESC = embryonic stem cell; IMRT = intensity-modulated radiation therapy; NSC = neural stem cell; OPC = oligodendrocyte progenitor cell; SRS = stereotactic radiosurgery; WBRT = whole-brain radiation therapy.

SUBMITTED January 4, 2016. ACCEPTED February 24, 2016.

INCLUDE WHEN CITING DOI: 10.3171/2016.2.FOCUS161. 
to provide meaningful regenerative therapies to those who have battled with brain tumors and lived to suffer the long-term consequences of current treatments.

\section{Multiple Paths to Radiation-Induced Brain Injury}

Of the various forms of radiotherapy, WBRT carries the greatest risk of iatrogenic cognitive impairment. Although it was once administered prophylactically to those with childhood leukemia, WBRT has increasingly become a judiciously administered therapy in children since the realization of its devastating cognitive consequences. The adult brain has historically been considered relatively refractory to WBRT, which is administered to roughly 200,000 cancer patients per year. ${ }^{71}$ Increasing recognition of the cognitive toll incurred by adults following WBRT is now prompting critical reevaluation of the role of WBRT in adults with brain metastases?

At the other extreme, stereotactic radiosurgery (SRS) minimizes off-target radiation exposure, serving as an adjunct to or alternative for discrete resections. Given the minimally invasive nature of SRS, and its ability to treat new additional new lesions over time, SRS, in combination with close follow-up, may increasingly enable avoidance of up-front WBRT in patients with brain metastases. ${ }^{7}$ The higher focal doses of radiation employed with SRS, however, are not entirely without consequence. In a recent consecutive series of 271 brain metastases treated with stereotactic radiosurgery, follow-up examination, at a median of 17.2 months, revealed radionecrosis in $25.8 \%$ of patients, two-thirds of whom were symptomatic. The incidence of radionecrosis in those followed up out to 24 months was 34\% ${ }^{37}$ Although not the focus of this review, much remains to be learned about the pathophysiology of radionecrosis, a severe, albeit focal form of radiationinduced brain injury.

Intensity-modulated radiation therapy (IMRT) provides broader radiation coverage than SRS but can be contoured to spatially tailor the radiation field. Given the particularly critical role of the hippocampus and hippocampal stem cells for learning and memory, and the sensitivity of this region to radiation, IMRT has recently been used to perform hippocampus-avoiding WBRT in an attempt to minimize cognitive dysfunction. ${ }^{23}$ Importantly, radiation therapy for skull base tumors via IMRT and proton-beam radiotherapy can also yield substantial radiation doses to the nearby temporal lobe, inducing parenchymal injury and cognitive impairment. ${ }^{15,55}$

\section{Mechanisms of Radiation-Induced Brain Injury \\ Cytotoxicity and Neuroinflammation}

Radiation deposits energy into cellular biomolecules, producing chemical changes including DNA damage. Radiolysis of water generates reactive oxygen species, which are potently amplified via radiation-induced damage to energy-producing mitochondria, leading then to further damage of cellular nucleic acids, proteins, and lipids, as well as components of the extracellular matrix. ${ }^{38}$ Local tissue injury prompts activation of microglia, the effector cells of the brain's innate immune system..$^{21,56} \mathrm{An}$ initial wave of acute radiation-induced microglial activation and neuroinflammation is then followed by a persistently activated microglial state that may last for decades. ${ }^{59}$ Activated microglia secrete inflammatory cytokines and produce reactive oxygen species, potentially thereby serving to propagate an ongoing cascade of chronic neuroinflammation-one that has been correlated with impairments in hippocampal neurogenesis and cognitive function. ${ }^{29,39,57}$ We recently demonstrated that the transcriptional profile of radiated microglia closely mirrors that acquired by microglia during aging ${ }^{42}$-itself the single greatest risk factor for cognitive decline and neurodegenerative disease.

\section{Impact of Radiation on Neurogenesis and Neuronal Function}

Mounting evidence in recent years has linked hippocampal neurogenesis with cognitive functions including learning, memory, and spatial navigation. ${ }^{48,70,72}$ Indeed, the profound impact of brain irradiation on neurogenesis has led to its becoming the gold-standard laboratory technique to abolish neurogenesis in animal models., ${ }^{4,56,57,83,96}$ Although the mechanisms are not fully understood, a link between persistent microglial activation and impaired hippocampal neurogenesis has been reported. ${ }^{57,58}$ It is now known that although radiation kills rapidly dividing neural progenitor cells, the more quiescent neural stem cells (NSCs) remain viable after brain radiation, albeit in a persistently quiescent state only modestly responsive to proneurogenic stimuli such as voluntary physical exercise and mitogenic stimulation. ${ }^{60,93}$ Unfortunately, radiation's failure to kill quiescent NSCs mirrors its inability to kill quiescent glioma stem cells, which reestablish a typically more aggressive and resistant recurrent malignancy.

As a model, radiation-induced ablation of neurogenesis was previously used specifically to illustrate the importance of neurogenesis to cognition ${ }^{54,74,75}$ However, radiation is now known to impact the spectrum of CNS cell types, including neurons themselves that manifest altered synaptic morphology, function, and plasticity. ${ }^{34,46,73,89}$ Of particular therapeutic relevance are the effects of radiation on the oligodendrocytic lineage.

\section{Radiation and White Matter Degeneration}

Progressive white matter "atrophy" is a hallmark of radiation-induced brain injury. ${ }^{86}$ Oligodendrocytes are exquisitely sensitive to radiation due in part to their high metabolic demand and mitochondrial content, leaving them susceptible to oxidative stress and bioenergetic failure. ${ }^{32}$ Superimposed microvascular injury has also been implicated in both delayed white matter injury and radiation necrosis. ${ }^{14,62,95}$ In contrast to other mechanisms of demyelination, surviving endogenous progenitor cells are intrinsically dysfunctional following radiation, impeding the usual reparative responses of NSCs and oligodendrocyte progenitor cells (OPCs). As such, radiation results in a pervasive pattern of OPC loss and progressive demyelination that has been well characterized in rodents and humans. ${ }^{65}$ Given the particular importance of white 
matter in cognitive tasks of working memory and executive function, diffuse white matter degeneration is a major contributor to radiation-induced cognitive impairment. Although this review focuses on the effects of radiation on oligodendrocyte progenitor cells, it should be noted that OPC function is additionally impaired by certain chemotherapeutic agents, ${ }^{26,30}$ the combinatorial effects of which further exacerbate white matter atrophy following treatment of brain tumors.

\section{White Matter as a Target for Regeneration Myelin: A Dynamic and Resilient Contributor to Cognition}

Axons within CNS white matter tracts depend on myelin for function and long-term survival. ${ }^{68}$ Increasing evidence reveals a dynamic cross-talk between neurons, oligodendrocytes, and OPCs, with white matter "plasticity" now understood to be integral to cognitive function. $22,51,69$ Several diseases affect white matter, ranging from multiple sclerosis to childhood leukodystrophies, and have prompted development of several animal models of demyelination. One such genetic model of oligodendrocyte ablation revealed acute axonal injury even preceding ultrastructurally detectable loss of myelin membranes, illustrating the dependence of neurons on functional oligodendrocytes. ${ }^{63}$ Nevertheless, most forms of acute demyelination, including toxin-induced demyelination, are followed by generation of new oligodendrocytes by local white matter OPCs and subventricular zone NSC-derived OPCs. These swiftly remyelinate the lesioned area, averting permanent axonal injury. ${ }^{66}$ Encouragingly, adult animal models of even widespread oligodendrocyte loss - arguably more "severe" than that seen in human patients after radiation-induced brain injury ${ }^{65}$ - reveal that surviving healthy OPCs can efficiently and effectively remyelinate denuded axons throughout the brain. ${ }^{88}$ Moreover, self-regulation of OPC number and distribution throughout the brain appears hardwired into the very identity of OPCs, such that any number of experimental strategies to remove them from the brain either during or after development is met with remarkably swift and complete proliferation and migration of remaining OPCs to restore normal numbers and distribution throughout the brain.,35 Given these potent regenerative capabilities, OPCs represent a promising avenue for treatment of radiation-induced brain injury.

\section{Cell Therapies for Radiation-Induced Brain Injury: Proof of Principle}

Although endogenous OPCs are rendered dysfunctional and unable to proliferate by brain radiation, healthy functioning exogenous OPCs maintain their normal function upon implantation into a previously irradiated brain or spinal cord, where they can migrate widely, generate oligodendrocytes, and remyelinate lesioned areas. ${ }^{19,20,31}$ In the 1990s, Franklin et al. noted that implanted OPCs could engraft into the spinal cord following either chemical- or radiation-induced demyelination, though they were unable to traverse areas of normal nonradiated tissue to reach areas of radiation or focal demyelination. ${ }^{19,20}$ In fact, remyelination by grafted cells was only observed in regions completely devoid of endogenous OPCs. ${ }^{28}$ Conversely, Monje et al. in 2002 grafted bromodeoxyuridine (BrdU)-labeled NSCs into irradiated rat brains and found relatively poor survival of transplanted cells and lower rates of neuronal differentiation in the irradiated, relative to the nonirradiated, microenvironment. ${ }^{57}$ Interpretation of these data is tricky, since most cells die after transplantation, and BrdU was subsequently found able to be recycled from dead transplanted cells to be taken up by endogenous dividing cells in the area. ${ }^{10}$ As such, the apparently poor survival of NSCs in the irradiated hippocampus may have simply reflected the lower rates of endogenous neurogenesis following brain irradiation. ${ }^{57}$ Irvine and Blakemore in 2007 grafted early passage neurospheres from an E14 GFP-labeled mouse into the lateral ventricles of mice lesioned with 40 Gy of x-irradiation. Fourteen days later, grafted GFP-positive cells were widely distributed in areas of significant radiation-induced injury wherein the endogenous NG2-positive OPCs had been fully ablated. However, no engraftment was seen in regions with surviving OPCs. ${ }^{31}$ Consistent with this, Niranjan et al. found that survival of grafted mouse NSCs could be improved by WBRT (20 or 40 Gy) 7 days before cell injection. ${ }^{61}$ In further support of cell transplantation, models of local demyelination demonstrated several-fold faster and more complete remyelination with exogenous cell delivery than could occur by replying upon adjacent surviving OPCs. ${ }^{6}$

\section{Preclinical Cognitive Benefits}

In 2009 and 2011, Acharya et al. performed the first studies aimed specifically at evaluating the role of grafted cells for treating radiation-induced cognitive impairment in rats, using human embryonic stem cells (ESCs) and human NSCs, respectively. ${ }^{2,3}$ In both reports, cells were injected into the hippocampus 2 days after delivering a 10-Gy dose of whole-brain radiation, yielding improved performance on hippocampus-dependent cognitive tasks. Although evidence of surviving cells was provided via human nuclei staining at 1 month after transplantation, claims of neural differentiation were supported only by colocalization of neuronal markers with BrdU, which may again have reflected endogenous neurogenesis. Indeed, we recently observed that GFP-labeled ESC-derived NPCs injected into the irradiated mouse hippocampus not only generated a small number of new graft-derived neurons, but also ameliorated local levels of endogenous neurogenesis via presumably trophic effects (TC Burns, unpublished observations). As such, implanted NSCs may augment cognition following brain irradiation by helping to replenish endogenous OPCs and enhancing endogenous hippocampal neurogenesis, among other as yet ill-defined trophic mechanisms.

In 2015, Piao et al. used human ESC-derived OPCs in a rat model treated with a clinically relevant regimen of 40 Gy of fractionated radiation. As predicted from the aforementioned studies, the healthy, nonirradiated OPCs migrated widely from their points of implantation to broadly remyelinate the CNS. Interestingly, implanted OPCs yielded cognitive recovery when implanted into the forebrain, whereas injections into the cerebellum prompted motor recovery ${ }^{67}$ Given that radiation-induced brain injury yields a broad array of pathological changes spanning endothe- 
lium, microglia, and neuronal synapses, as well as OPCs, observations of a single cellular intervention (OPCs), which yields remarkable levels of functional recovery approximating performance of nonirradiated animals, portends optimism that other potentially secondary cellular changes may be mitigated by restoration of OPCs and myelin function. Alternatively, OPCs, may also possess trophic and supportive functions in similar manner to NSCs, such as ability to modulate inflammation, secrete neuroprotective compounds, promote endogenous neurogenesis augment neuronal plasticity. ${ }^{12,85}$ As such, OPC transplantation may mediate behavioral recovery via multiple synergistic actions of cell replacement, avoiding secondary cellular changes consequent to myelin and OPC loss, as well as potentially a plethora of other trophic mechanisms.

\section{Which Cell Types for Human Trials?}

Primary OPCs have been evaluated in preclinical models of several diseases, including multiple sclerosis, childhood hypomyelinating disorders, traumatic brain injury, and stroke among others. ${ }^{94}$ In a Geron-sponsored trial for spinal cord injury, ESC-derived OPCs became the world's first ESC-derived cell product to be used in a human clinical trial. Despite evidence of safety, the study was terminated prematurely for financial reasons..$^{18,79}$ OPCs seem particularly well suited to radiation-induced brain injury, given the inherent demyelinating process, the widespread loss of endogenous OPCs, and remarkable migratory behavior of transplanted OPCs following radiation-induced depletion of endogenous progenitors in animal models.

A well-characterized line of fetal-derived NSCs was employed for a Phase I clinical trial for Pelizaeus-Merzbacher disease, a rare childhood leukodystrophy; MRI findings from these patients provided the first human in vivo evidence of stem cell-derived myelin production..$^{25}$ As such, since NSCs also differentiate into OPCs that generate myelin in vivo after experimental brain irradiation, improve cognitive function in animal models of brain radiation, ${ }^{2,3}$ and demonstrate a host of well-documented trophic effects, NSCs and OPCs may both represent appropriate candidates for clinical trials of radiation-induced brain injury.

OPCs and NSCs may be derived from either fetal brains or ESCs. Additionally, the feasibility of generating induced pluripotent stem cell-derived cells for transplantation offers the potential to avoid immunosuppression, an increasingly relevant consideration given the emerging promise of novel immunotherapies for primary and metastatic brain tumors.

\section{Potential Pitfalls and Challenges Cell Distribution in the Human Brain}

One of the major challenges to translation of rodent to human studies for neuroregeneration is the sheer size of the human brain. While systemically delivered (intravenous or intraarterial) therapies are easily scaled by increasing cell numbers, and, focal targeted therapies for stroke or Parkinson's disease are feasible with multiple needle passes to the relatively small affected area, the prospect of treating an entire human brain is rather more daunting. While a few millimeters of cell migration from the site of implantation may be sufficient to broadly remyelinate a mouse brain, ${ }^{82,90,92}$ the human brain is over 3000 times the size of a mouse brain. As such almost epic migratory feats would be required to achieve more than paltry benefit. Fortunately, the very presence of prior radiation is well documented to promote migration and wide distribution of implanted OPCs in the CNS. Nevertheless, preclinical work in rats suggested that cells implanted into the forebrain failed to migrate into the cerebellum and vice versa ${ }^{67}$ Such data suggest finite limits to migratory capacity, increasing the probability of requiring multiple delivery sites in a human subjects. Although the very biology of OPCs provides reason to be optimistic that they will proliferate in vivo and achieve increasingly broad and uniform distribution after implantation, only pilot clinical trials in humans will enable this question to be adequately answered.

\section{Unique Properties of Human White Matter}

Rodent OPCs proliferate throughout life, and new OPCderived oligodendrocytes contribute actively to cognitive function..$^{22,50}$ White matter is also dynamically regulated in humans, with increased local fractional anisotropy detected in adult subjects after training in a complex visuomotor task ${ }^{78}$ or learning a second language. ${ }^{77}$ However, in contrast to mice, radiocarbon dating of cells in the human brain has indicated that very few human oligodendrocytes are born after early childhood..$^{77}$ These data suggest that adult human white matter plasticity occurs at the level of postmitotic oligodendrocytes rather than via generation of new olidodendrocytes from endogenous OPCs, as has been documented in rodents. ${ }^{22}$ Whether this apparent species-specific variability in adult white matter plasticity could impede human remyelination from implanted OPCs after radiation injury will need to be established empirically. However, given that human OPCs engage in some degree of remyelination in the early stages of multiple sclerosis, and can successfully remyelinate an entire mammalian brain in xenograft studies, strong proof of principle points to remyelinating OPCs successfully engrafting into the vacated OPC niche following human brain irradiation.

\section{Could Progenitor Cells Poke the Sleeping Dragon?}

A dynamic tension exists between neurooncology and neuroregeneration. Whereas neuroregenerative strategies may promote cell survival, proliferation and migration, malignant brain tumors are themselves the product of $e x$ cessive cell survival, proliferation, and migration. Could introducing these "ingredients of malignancy" into a brain already afflicted with neoplasia be the equivalent of poking the proverbial sleeping dragon? Tumorigenesis is already perhaps the single greatest risk of regenerative strategies, with cell therapies, with avenues to tumorigenesis including teratomas from residual undifferentiated pluripotent (ESCs and induced pluripotent stem cells), malignant transformation of in vitro cultured cell lines, and even epigenetic drift of cultured cells into a more primitive germ cell-like state. ${ }^{41,44}$ While vigilance to avoid direct graft-induced tumorigenesis is obviously paramount, 
could implanted cells also secrete a cocktail of trophic and proangiogenic molecules ${ }^{11,13}$ that could reactivate residual or dormant tumor cells in the previously irradiated patient? Vigilant monitoring for neoplasia of any type, be it recurrent or graft derived, with serial imaging or biomarkers will be absolutely critical in neuroregenerative trials for radiation-induced brain injury. We speculate that such risks may be lower with cellular therapies than with strategies aiming to "reactivate" endogenous progenitors via growth factor infusion, as has been considered for other CNS diseases. ${ }^{76,98}$ In fact, NSCs themselves exhibit innate antitumor properties. ${ }^{84}$ Given the migratory capacity of OPCs throughout previously irradiated brain, and the tropism of many progenitor cell types for tumors, ${ }^{1,17,43,87}$ OPCs or NSCs engineered to additionally produce antitumor and/or proregenerative molecules may enable broad delivery of protective and regenerative cells throughout irradiated portions of the CNS. In this manner, neurooncology patients in the future may receive therapies designed to be simultaneously regenerative and antineoplastic, not only restoring white matter but remaining in place to secrete antineoplastic compounds and serve as sentinel first responders in the event of recurrent disease.

\section{A Word of Caution Regarding Glioma Immunotherapies}

Glioma stem cells are of increasing interest as a target for novel immunotherapeutic strategies. ${ }^{33,47,81}$ Given the very close relationship between glioma stem cells and endogenous progenitor cells, strategies immunologically targeting specific markers of NSCs and OPCs present tempting targets to achieve oncological control in primary brain tumors. ${ }^{27}$ However, preclinical models have demonstrated an appropriately trained immune system of being quite capable of entirely ablating endogenous OPCs. ${ }^{40}$ While this strategy may provide a valuable opportunity to functionally interrogate the roles of OPCs in preclinical models, active immunization against molecules expressed by endogenous stem or progenitor cells will predictably lead to patients suffering from the resultant cognitive effects of ablated progenitor populations. Moreover, such patients would, from that point forward, rapidly reject any therapeutically implanted progenitor cells, making the resultant cognitive deficits irreversible.

\section{Work in Progress}

Once a decision has been made to proceed with clinical translation, innumerable perhaps mundane but critical questions arise, often requiring educated guesses in light of practical differences between humans and preclinical rodents. Some questions, for example, are as follows: What are the appropriate inclusion/exclusion criteria? What type and origin of cells should be used-autologous or allogeneic? How many cells are needed in the larger human brain? When after injury should they be delivered? What is the optimal site(s) of delivery? What adjuvant therapies would facilitate optimal survival, integration, and function? Should label(s) be considered for subsequent detection via MRI or postmortem histology?

Behind optimizing each of these decisions is the motivation to detect a meaningful biological response in a "positive" trial, which is often in large part dependent on selecting the appropriate outcome measure. Perhaps more important than a given trial being "positive," however, is the data gained from even incompletely successful outcomes. Fortunately, the quantity and quality of biological data obtainable that can be incorporated into such trials is increasing exponentially. Brain tumor mutations can now be detected in the cell-free DNA of cerebrospinal fluid. ${ }^{64,91}$ In a recent proof-of-principle study, elevated cell-free RNA transcripts of APP and PSD3 were identified in the serum of patients diagnosed with Alzheimer's disease, while transcripts associated with neural development were detectable in peripheral blood of women during pregnancy. ${ }^{36}$ Plasma phospholipid profiles can now identify patients expected to develop age-related memory impairment within 2-3 years, with over $90 \%$ accuracy. ${ }^{49}$ Such techniques, in combination with cell-type specific transcriptome analysis of CNS samples from previously irradiated patients at time of surgery, ${ }^{16,42,99}$ may enable unprecedented windows into human CNS pathophysiology and responses to putative therapies.

\section{Unique Advantages of Radiation Injury for Translational Neuroregeneration}

Radiation-induced brain injury offers unparalleled opportunity to study human CNS disease, regardless of the proposed therapy under consideration. In virtually no other CNS disease can the patient be studied prior to, during, and after injury in a longitudinal and even scheduled manner. Stroke, spinal cord injury, and traumatic brain injury literature abound with neuroprotective compounds that are most effective when given prior to the actual injury. Of course, progenitor cells should be administered only after radiation to avoid damage to the implanted cells by the radiation. Moreover, certain other therapies such as antioxidants could conceivably reduce radiation efficacy if administered prior to radiation. Nevertheless, the availability of this coveted "preinjury" window of opportunity sets radiation-induced brain injury apart from other CNS injuries and diseases as an ideal candidate for trials of appropriate neuroprotective agents, ideally in conjunction with systematic acquisition of detailed baseline and longitudinal outcomes data.

Traumatic brain injury, spinal cord injury, and stroke are notoriously heterogeneous. Even most neurodegenerative diseases vary widely in severity and rate of progression. Radiation-induced brain injury offers an uncommon opportunity to study the efficacy of a neuroprotective or neuroregenerative therapy in patients who all receive the identical lesion in a virtually identical manner. Moreover, in contrast to spinal cord injury-the only condition yet treated with OPCs, and which occurs in approximately 12,000 patients per year-WBRT is currently administered to roughly 200,000 patients per year in the United States, greatly enhancing the feasibility of clinical trials.

Much of the failure to develop effective therapies for CNS disease has been attributed to preclinical studies being predominantly focused upon animal models that poorly replicate human disease. To date, for example, no transcriptome data exist in public databases for human CNS 
tissue following stroke, traumatic brain injury, or spinal cord injury, although such data abound for mice and rats. Previously irradiated brain tissue is surgically accessible at the margin of tumor resections, in both a delayed manner for recurrent disease and acutely in the case of neoadjuvant radiation therapy, providing unprecedented opportunities to study and understand the human pathophysiological responses to CNS injury. Indeed, remarkable overlap exists between neurological and inflammatory diseases within species, allowing extrapolations that are impossible across different species. ${ }^{9,80}$ That is to say, the transcriptome of human traumatic brain injury is likely much more closely related to human radiation injury than it is to mouse traumatic brain injury. As such, insights gained in the course of developing therapies for human radiation-induced brain injury may provide exceptional insights into human CNS aging, traumatic injury, and neurodegeneration. ${ }^{9,42}$

Unfortunately, most patients with metastatic tumors to the CNS die of their malignancy within 2 years from diagnosis of CNS involvement. Since cognitive deficits may present within 3 months of brain radiation, and experimental regenerative therapies may be employed to enhance cognition and quality of remaining life despite the likelihood of recurrent systemic disease, autopsy tissue may frequently become available for the assessment of outcomes and refinement of methodologies within a shorter time frame than for almost any other neurological disease. Though a stark reminder of the work ahead to improve cancer treatments, such direct and timely access to the brains of those treated with regenerative therapies will be invaluable for iterative advances toward more effective therapies in the future.

\section{Conclusions}

In 1928 Ramón y Cajal wrote in his book Degeneration and Regeneration of the Nervous System: "In adult centres the nerve paths are something fixed, ended, immutable. Everything may die, nothing may be regenerated. It is for the science of the future to change, if possible, this harsh decree." We now have sufficient evidence that this harsh decree can be changed and argue that radiation-induced brain injury offers low-hanging fruit to realize Cajal's "science of the future."

\section{References}

1. Aboody KS, Brown A, Rainov NG, Bower KA, Liu S, Yang W, et al: Neural stem cells display extensive tropism for pathology in adult brain: evidence from intracranial gliomas. Proc Natl Acad Sci U S A 97:12846-12851, 2000

2. Acharya MM, Christie LA, Lan ML, Donovan PJ, Cotman CW, Fike JR, et al: Rescue of radiation-induced cognitive impairment through cranial transplantation of human embryonic stem cells. Proc Natl Acad Sci U S A 106:19150-19155, 2009

3. Acharya MM, Christie LA, Lan ML, Giedzinski E, Fike JR, Rosi S, et al: Human neural stem cell transplantation ameliorates radiation-induced cognitive dysfunction. Cancer Res 71:4834-4845, 2011

4. Bellinzona M, Gobbel GT, Shinohara C, Fike JR: Apoptosis is induced in the subependyma of young adult rats by ionizing irradiation. Neurosci Lett 208:163-166, 1996

5. Bergles DE, Richardson WD: Oligodendrocyte development and plasticity. Cold Spring Harb Perspect Biol 8:a020453, 2015

6. Blakemore WF, Irvine KA: Endogenous or exogenous oligodendrocytes for remyelination. J Neurol Sci 265:43-46, 2008

7. Brown PD, Asher AL, Ballman KV, Farace E, Cerhan JH, Anderson SK, et al: NCCTG N0574 (Alliance): a phase III randomized trial of whole brain radiation therapy (WBRT) in addition to radiosurgery (SRS) in patients with 1 to 3 brain metastases. J Clin Oncol 33 Suppl:LBA4, 2015 (Abstract)

8. Brown PD, Pugh S, Laack NN, Wefel JS, Khuntia D, Meyers C, et al: Memantine for the prevention of cognitive dysfunction in patients receiving whole-brain radiotherapy: a randomized, double-blind, placebo-controlled trial. Neuro Oncol 15:1429-1437, 2013

9. Burns TC, Li MD, Mehta S, Awad AJ, Morgan AA: Mouse models rarely mimic the transcriptome of human neurodegenerative diseases: A systematic bioinformatics-based critique of preclinical models. Eur J Pharmacol 759:101-117, 2015

10. Burns TC, Ortiz-González XR, Gutiérrez-Pérez M, Keene CD, Sharda R, Demorest ZL, et al: Thymidine analogs are transferred from prelabeled donor to host cells in the central nervous system after transplantation: a word of caution. Stem Cells 24:1121-1127, 2006

11. Burns TC, Steinberg GK: Stem cells and stroke: opportunities, challenges and strategies. Expert Opin Biol Ther 11:447-461, 2011

12. Burns TC, Verfaillie CM: From mice to mind: Strategies and progress in translating neuroregeneration. Eur J Pharmacol 759:90-100, 2015

13. Burns TC, Verfaillie CM, Low WC: Stem cells for ischemic brain injury: a critical review. J Comp Neurol 515:125-144, 2009

14. Coderre JA, Morris GM, Micca PL, Hopewell JW, Verhagen I, Kleiboer BJ, et al: Late effects of radiation on the central nervous system: role of vascular endothelial damage and glial stem cell survival. Radiat Res 166:495-503, 2006

15. Combs SE, Kessel K, Habermehl D, Haberer T, Jäkel O, Debus J: Proton and carbon ion radiotherapy for primary brain tumors and tumors of the skull base. Acta Oncol 52:15041509,2013

16. Darmanis S, Sloan SA, Zhang Y, Enge M, Caneda C, Shuer LM, et al: A survey of human brain transcriptome diversity at the single cell level. Proc Natl Acad Sci U S A 112:72857290,2015

17. Doucette T, Rao G, Yang Y, Gumin J, Shinojima N, Bekele BN, et al: Mesenchymal stem cells display tumor-specific tropism in an RCAS/Ntv-a glioma model. Neoplasia 13:716725, 2011

18. Eaton ML, Kwon BK, Scott CT: Money and morals: ending clinical trials for financial reasons. Curr Top Behav Neurosci 19:297-315, 2015

19. Franklin RJ, Bayley SA, Blakemore WF: Transplanted CG4 cells (an oligodendrocyte progenitor cell line) survive, migrate, and contribute to repair of areas of demyelination in $\mathrm{X}$-irradiated and damaged spinal cord but not in normal spinal cord. Exp Neurol 137:263-276, 1996

20. Franklin RJ, Bayley SA, Milner R, Ffrench-Constant C, Blakemore WF: Differentiation of the O-2A progenitor cell line CG-4 into oligodendrocytes and astrocytes following transplantation into glia-deficient areas of CNS white matter. Glia 13:39-44, 1995

21. Gebicke-Haerter PJ: Microglia in neurodegeneration: molecular aspects. Microsc Res Tech 54:47-58, 2001

22. Gibson EM, Purger D, Mount CW, Goldstein AK, Lin GL, Wood LS, et al: Neuronal activity promotes oligodendrogenesis and adaptive myelination in the mammalian brain. Science 344:1252304, 2014

23. Gondi V, Pugh SL, Tome WA, Caine C, Corn B, Kanner A, et 
al: Preservation of memory with conformal avoidance of the hippocampal neural stem-cell compartment during wholebrain radiotherapy for brain metastases (RTOG 0933): a phase II multi-institutional trial. J Clin Oncol 32:3810-3816, 2014

24. Greene-Schloesser D, Robbins ME: Radiation-induced cognitive impairment-from bench to bedside. Neuro Oncol 14 (Suppl 4):iv37-iv44, 2012

25. Gupta N, Henry RG, Strober J, Kang SM, Lim DA, Bucci M, et al: Neural stem cell engraftment and myelination in the human brain. Sci Transl Med 4:155ra137, 2012

26. Han R, Yang YM, Dietrich J, Luebke A, Mayer-Pröschel M, Noble M: Systemic 5-fluorouracil treatment causes a syndrome of delayed myelin destruction in the central nervous system. J Biol 7:12, 2008

27. Higgins SC, Fillmore HL, Ashkan K, Butt AM, Pilkington GJ: Dual targeting NG2 and GD3A using Mab-Zap immunotoxin results in reduced glioma cell viability in vitro. Anticancer Res 35:77-84, 2015

28. Hinks GL, Chari DM, O'Leary MT, Zhao C, Keirstead HS, Blakemore WF, et al: Depletion of endogenous oligodendrocyte progenitors rather than increased availability of survival factors is a likely explanation for enhanced survival of transplanted oligodendrocyte progenitors in X-irradiated compared to normal CNS. Neuropathol Appl Neurobiol 27:59-67, 2001

29. Hong JH, Chiang CS, Campbell IL, Sun JR, Withers HR, McBride WH: Induction of acute phase gene expression by brain irradiation. Int J Radiat Oncol Biol Phys 33:619-626, 1995

30. Hyrien O, Dietrich J, Noble M: Mathematical and experimental approaches to identify and predict the effects of chemotherapy on neuroglial precursors. Cancer Res 70:1005110059, 2010

31. Irvine KA, Blakemore WF: A different regional response by mouse oligodendrocyte progenitor cells (OPCs) to high-dose $\mathrm{X}$-irradiation has consequences for repopulating OPC-depleted normal tissue. Eur J Neurosci 25:417-424, 2007

32. Ishii A, Dutta R, Wark GM, Hwang SI, Han DK, Trapp BD, et al: Human myelin proteome and comparative analysis with mouse myelin. Proc Natl Acad Sci U S A 106:14605-14610, 2009

33. Ji J, Judkowski VA, Liu G, Wang H, Bunying A, Li Z, et al: Identification of novel human leukocyte antigen- $A^{*} 0201-$ restricted, cytotoxic T lymphocyte epitopes on CD133 for cancer stem cell immunotherapy. Stem Cells Transl Med 3:356-364, 2014

34. Kempf SJ, Sepe S, von Toerne C, Janik D, Neff F, Hauck SM, et al: Neonatal Irradiation Leads to Persistent Proteome Alterations Involved in Synaptic Plasticity in the Mouse Hippocampus and Cortex. J Proteome Res 14:4674-4686, 2015

35. Kessaris N, Fogarty M, Iannarelli P, Grist M, Wegner M, Richardson WD: Competing waves of oligodendrocytes in the forebrain and postnatal elimination of an embryonic lineage. Nat Neurosci 9:173-179, 2006

36. Koh W, Pan W, Gawad C, Fan HC, Kerchner GA, WyssCoray T, et al: Noninvasive in vivo monitoring of tissuespecific global gene expression in humans. Proc Natl Acad Sci U S A 111:7361-7366, 2014

37. Kohutek ZA, Yamada Y, Chan TA, Brennan CW, Tabar V, Gutin $\mathrm{PH}$, et al: Long-term risk of radionecrosis and imaging changes after stereotactic radiosurgery for brain metastases. J Neurooncol 125:149-156, 2015

38. Leach JK, Van Tuyle G, Lin PS, Schmidt-Ullrich R, Mikkelsen RB: Ionizing radiation-induced, mitochondria-dependent generation of reactive oxygen/nitrogen. Cancer Res 61:3894-3901, 2001

39. Lee WH, Sonntag WE, Mitschelen M, Yan H, Lee YW: Irradiation induces regionally specific alterations in pro- inflammatory environments in rat brain. Int J Radiat Biol 86:132-144, 2010

40. Leoni G, Rattray M, Fulton D, Rivera A, Butt AM: Immunoablation of cells expressing the NG2 chondroitin sulphate proteoglycan. J Anat 224:216-227, 2014

41. Leten C, Roobrouck VD, Struys T, Burns TC, Dresselaers T, Vande Velde G, et al: Controlling and monitoring stem cell safety in vivo in an experimental rodent model. Stem Cells 32:2833-2844, 2014

42. Li MD, Burns TC, Kumar S, Morgan AA, Sloan SA, Palmer TD: Aging-like changes in the transcriptome of irradiated microglia. Glia 63:754-767, 2015

43. Li Q, Wijesekera O, Salas SJ, Wang JY, Zhu M, Aprhys C, et al: Mesenchymal stem cells from human fat engineered to secrete BMP4 are nononcogenic, suppress brain cancer, and prolong survival. Clin Cancer Res 20:2375-2387, 2014

44. Lo Nigro A, Geraerts M, Notelaers T, Roobrouck VD, Muijtjens M, Eggermont K, et al: MAPC culture conditions support the derivation of cells with nascent hypoblast features from bone marrow and blastocysts. J Mol Cell Biol 4:423426, 2012

45. Mabbott DJ, Spiegler BJ, Greenberg ML, Rutka JT, Hyder DJ, Bouffet E: Serial evaluation of academic and behavioral outcome after treatment with cranial radiation in childhood. J Clin Oncol 23:2256-2263, 2005

46. Machida M, Lonart G, Britten RA: Low (60 cGy) doses of ${ }^{56} \mathrm{Fe}$ HZE-particle radiation lead to a persistent reduction in the glutamatergic readily releasable pool in rat hippocampal synaptosomes. Radiat Res 174:618-623, 2010

47. Madany M, Thomas TM, Edwards L, Yu JS: Immunobiology and immunotherapeutic targeting of glioma stem cells. Adv Exp Med Biol 853:139-166, 2015

48. Madsen TM, Kristjansen PE, Bolwig TG, Wörtwein G: Arrested neuronal proliferation and impaired hippocampal function following fractionated brain irradiation in the adult rat. Neuroscience 119:635-642, 2003

49. Mapstone M, Cheema AK, Fiandaca MS, Zhong X, Mhyre TR, MacArthur LH, et al: Plasma phospholipids identify antecedent memory impairment in older adults. Nat Med 20:415-418, 2014

50. McKenzie IA, Ohayon D, Li H, de Faria JP, Emery B, Tohyama $\mathrm{K}$, et al: Motor skill learning requires active central myelination. Science 346:318-322, 2014

51. Mensch S, Baraban M, Almeida R, Czopka T, Ausborn J, El Manira A, et al: Synaptic vesicle release regulates myelin sheath number of individual oligodendrocytes in vivo. Nat Neurosci 18:628-630, 2015

52. Merchant TE, Conklin HM, Wu S, Lustig RH, Xiong X: Late effects of conformal radiation therapy for pediatric patients with low-grade glioma: prospective evaluation of cognitive, endocrine, and hearing deficits. J Clin Oncol 27:3691-3697, 2009

53. Merchant TE, Schreiber JE, Wu S, Lukose R, Xiong X, Gajjar A: Critical combinations of radiation dose and volume predict intelligence quotient and academic achievement scores after craniospinal irradiation in children with medulloblastoma. Int J Radiat Oncol Biol Phys 90:554-561, 2014

54. Meshi D, Drew MR, Saxe M, Ansorge MS, David D, Santarelli L, et al: Hippocampal neurogenesis is not required for behavioral effects of environmental enrichment. Nat Neurosci 9:729-731, 2006

55. Meyers CA, Geara F, Wong PF, Morrison WH: Neurocognitive effects of therapeutic irradiation for base of skull tumors. Int J Radiat Oncol Biol Phys 46:51-55, 2000

56. Mizumatsu S, Monje ML, Morhardt DR, Rola R, Palmer TD, Fike JR: Extreme sensitivity of adult neurogenesis to low doses of X-irradiation. Cancer Res 63:4021-4027, 2003

57. Monje ML, Mizumatsu S, Fike JR, Palmer TD: Irradiation induces neural precursor-cell dysfunction. Nat Med 8:955962,2002 
58. Monje ML, Toda H, Palmer TD: Inflammatory blockade restores adult hippocampal neurogenesis. Science 302:17601765,2003

59. Monje ML, Vogel H, Masek M, Ligon KL, Fisher PG, Palmer TD: Impaired human hippocampal neurogenesis after treatment for central nervous system malignancies. Ann Neurol 62:515-520, 2007

60. Naylor AS, Bull C, Nilsson MK, Zhu C, Björk-Eriksson T, Eriksson PS, et al: Voluntary running rescues adult hippocampal neurogenesis after irradiation of the young mouse brain. Proc Natl Acad Sci U S A 105:14632-14637, 2008

61. Niranjan A, Fellows W, Stauffer W, Burton EA, Hong CS, Lunsford LD, et al: Survival of transplanted neural progenitor cells enhanced by brain irradiation. J Neurosurg 107:383391, 2007

62. Okada S, Okeda R: Pathology of radiation myelopathy. Neuropathology 21:247-265, 2001

63. Oluich LJ, Stratton JA, Xing YL, Ng SW, Cate HS, Sah P, et al: Targeted ablation of oligodendrocytes induces axonal pathology independent of overt demyelination. J Neurosci 32:8317-8330, 2012

64. Pan W, Gu W, Nagpal S, Gephart MH, Quake SR: Brain tumor mutations detected in cerebral spinal fluid. Clin Chem 61:514-522, 2015

65. Panagiotakos G, Alshamy G, Chan B, Abrams R, Greenberg E, Saxena A, et al: Long-term impact of radiation on the stem cell and oligodendrocyte precursors in the brain. PLoS One 2:e588, 2007

66. Penderis J, Shields SA, Franklin RJ: Impaired remyelination and depletion of oligodendrocyte progenitors does not occur following repeated episodes of focal demyelination in the rat central nervous system. Brain 126:1382-1391, 2003

67. Piao J, Major T, Auyeung G, Policarpio E, Menon J, Droms L, et al: Human embryonic stem cell-derived oligodendrocyte progenitors remyelinate the brain and rescue behavioral deficits following radiation. Cell Stem Cell 16:198-210, 2015

68. Pohl HB, Porcheri C, Mueggler T, Bachmann LC, Martino G, Riethmacher D, et al: Genetically induced adult oligodendrocyte cell death is associated with poor myelin clearance, reduced remyelination, and axonal damage. J Neurosci 31:1069-1080, 2011

69. Purger D, Gibson EM, Monje M: Myelin plasticity in the central nervous system. Neuropharmacology [epub ahead of print], 2015

70. Raber J, Rola R, LeFevour A, Morhardt D, Curley J, Mizumatsu $\mathrm{S}$, et al: Radiation-induced cognitive impairments are associated with changes in indicators of hippocampal neurogenesis. Radiat Res 162:39-47, 2004

71. Rapp SR, Case LD, Peiffer A, Naughton MM, Chan MD, Stieber VW, et al: Donepezil for irradiated brain tumor survivors: a phase III randomized placebo-controlled clinical trial. J Clin Oncol 33:1653-1659, 2015

72. Rola R, Raber J, Rizk A, Otsuka S, VandenBerg SR, Morhardt DR, et al: Radiation-induced impairment of hippocampal neurogenesis is associated with cognitive deficits in young mice. Exp Neurol 188:316-330, 2004

73. Rosi S, Andres-Mach M, Fishman KM, Levy W, Ferguson RA, Fike JR: Cranial irradiation alters the behaviorally induced immediate-early gene arc (activity-regulated cytoskeleton-associated protein). Cancer Res 68:9763-9770, 2008

74. Santarelli L, Saxe M, Gross C, Surget A, Battaglia F, Dulawa $\mathrm{S}$, et al: Requirement of hippocampal neurogenesis for the behavioral effects of antidepressants. Science 301:805-809, 2003

75. Saxe MD, Battaglia F, Wang JW, Malleret G, David DJ, Monckton JE, et al: Ablation of hippocampal neurogenesis impairs contextual fear conditioning and synaptic plasticity in the dentate gyrus. Proc Natl Acad Sci U S A 103:1750117506, 2006

76. Scafidi J, Hammond TR, Scafidi S, Ritter J, Jablonska B,
Roncal M, et al: Intranasal epidermal growth factor treatment rescues neonatal brain injury. Nature 506:230-234, 2014

77. Schlegel AA, Rudelson JJ, Tse PU: White matter structure changes as adults learn a second language. J Cogn Neurosci 24:1664-1670, 2012

78. Scholz J, Klein MC, Behrens TE, Johansen-Berg H: Training induces changes in white-matter architecture. Nat Neurosci 12:1370-1371, 2009

79. Scott CT, Magnus D: Wrongful termination: lessons from the Geron clinical trial. Stem Cells Transl Med 3:1398-1401, 2014

80. Seok J, Warren HS, Cuenca AG, Mindrinos MN, Baker HV, $\mathrm{Xu} \mathrm{W}$, et al: Genomic responses in mouse models poorly mimic human inflammatory diseases. Proc Natl Acad Sci U S A 110:3507-3512, 2013

81. Silver DJ, Sinyuk M, Vogelbaum MA, Ahluwalia MS, Lathia JD: The intersection of cancer, cancer stem cells, and the immune system: therapeutic opportunities. Neuro Oncol 18:153-159, 2016

82. Sim FJ, McClain CR, Schanz SJ, Protack TL, Windrem MS, Goldman SA: CD140a identifies a population of highly myelinogenic, migration-competent and efficiently engrafting human oligodendrocyte progenitor cells. Nat Biotechnol 29:934-941, 2011

83. Snyder JS, Kee N, Wojtowicz JM: Effects of adult neurogenesis on synaptic plasticity in the rat dentate gyrus. J Neurophysiol 85:2423-2431, 2001

84. Stock K, Kumar J, Synowitz M, Petrosino S, Imperatore R, Smith ES, et al: Neural precursor cells induce cell death of high-grade astrocytomas through stimulation of TRPV1. Nat Med 18:1232-1238, 2012

85. Sypecka J, Sarnowska A: The neuroprotective effect exerted by oligodendroglial progenitors on ischemically impaired hippocampal cells. Mol Neurobiol 49:685-701, 2014

86. Szerlip N, Rutter C, Ram N, Yovino S, Kwok Y, Maggio W, et al: Factors impacting volumetric white matter changes following whole brain radiation therapy. J Neurooncol 103:111119,2011

87. Tang Y, Shah K, Messerli SM, Snyder E, Breakefield X, Weissleder R: In vivo tracking of neural progenitor cell migration to glioblastomas. Hum Gene Ther 14:1247-1254, 2003

88. Traka M, Arasi K, Avila RL, Podojil JR, Christakos A, Miller SD, et al: A genetic mouse model of adult-onset, pervasive central nervous system demyelination with robust remyelination. Brain 133:3017-3029, 2010

89. Vlkolinský R, Krucker T, Nelson GA, Obenaus A: ${ }^{56} \mathrm{Fe}-$ particle radiation reduces neuronal output and attenuates lipopolysaccharide-induced inhibition of long-term potentiation in the mouse hippocampus. Radiat Res 169:523-530, 2008

90. Wang S, Bates J, Li X, Schanz S, Chandler-Militello D, Levine C, et al: Human iPSC-derived oligodendrocyte progenitor cells can myelinate and rescue a mouse model of congenital hypomyelination. Cell Stem Cell 12:252-264, 2013

91. Wang Y, Springer S, Zhang M, McMahon KW, Kinde I, Dobbyn L, et al: Detection of tumor-derived DNA in cerebrospinal fluid of patients with primary tumors of the brain and spinal cord. Proc Natl Acad Sci U S A 112:9704-9709, 2015

92. Windrem MS, Nunes MC, Rashbaum WK, Schwartz TH, Goodman RA, McKhann G II, et al: Fetal and adult human oligodendrocyte progenitor cell isolates myelinate the congenitally dysmyelinated brain. Nat Med 10:93-97, 2004

93. Wong-Goodrich SJ, Pfau ML, Flores CT, Fraser JA, Williams CL, Jones LW: Voluntary running prevents progressive memory decline and increases adult hippocampal neurogenesis and growth factor expression after whole-brain irradiation. Cancer Res 70:9329-9338, 2010

94. Xu L, Ryu J, Hiel H, Menon A, Aggarwal A, Rha E, et al: Transplantation of human oligodendrocyte progenitor cells in 
an animal model of diffuse traumatic axonal injury: survival and differentiation. Stem Cell Res Ther 6:93, 2015

95. Yamaguchi N, Yamashima T, Yamashita J: A histological and flow cytometric study of dog brain endothelial cell injuries in delayed radiation necrosis. J Neurosurg 74:625-632, 1991

96. Yazlovitskaya EM, Edwards E, Thotala D, Fu A, Osusky KL, Whetsell WO Jr, et al: Lithium treatment prevents neurocognitive deficit resulting from cranial irradiation. Cancer Res 66:11179-11186, 2006

97. Yeung MS, Zdunek S, Bergmann O, Bernard S, Salehpour M, Alkass K, et al: Dynamics of oligodendrocyte generation and myelination in the human brain. Cell 159:766-774, 2014

98. Zachrisson O, Zhao M, Andersson A, Dannaeus K, Häggblad J, Isacson R, et al: Restorative effects of platelet derived growth factor-BB in rodent models of Parkinson's disease. J Parkinsons Dis 1:49-63, 2011

99. Zhang Y, Sloan SA, Clarke LE, Caneda C, Plaza CA, Blumenthal PD, et al: Purification and characterization of progenitor and mature human astrocytes reveals transcriptional and functional differences with mouse. Neuron 89:37-53, 2016

\section{Disclosures}

Dr. Burns has received research funding from the California Institute of Regenerative Medicine, which had no direct role in the research design or preparation of this manuscript.

\section{Author Contributions}

Conception and design: Burns. Drafting the article: Burns, Awad. Critically revising the article: Li, Grant. Approved the final version of the manuscript on behalf of all authors: Burns.

\section{Correspondence}

Terry C. Burns, Department of Neurosurgery, Stanford University, 300 Pasteur Dr., Stanford, CA 94305. email: tcburns@stanford. edu. 